
\title{
SOBRE A TEORIA DAS CLASSES SOCIAIS DE JESSÉ SOUZA I ON THE
} JESSÉ SOUZA'S THEORY OF SOCIAL CLASSES

\section{DAVID FRANCISCO LOPES GOMES}

RESUMO | Este artigo pretende discutir a teoria das classes sociais de Jessé Souza. Para tanto, começa apresentando uma síntese de sua teoria da modernidade. Em seguida, aborda as principais características pelas quais Jessé Souza define a "ralé", os "batalhadores" e as classes superiores - principalmente as classes médias. Por fim, conclui com alguns comentários críticos que podem vir a contribuir para o desenvolvimento futuro da discussão sobre classes sociais no Brasil.
ABSTRACT | This paper aims at discussing the Jesse Souza's theory of social classes. To do so, at first it presents a summary of his theory of modernity. Next, it approaches the main features by which Jesse Souza defines the "rabble", the "hard workers" and the upper classes mainly the middle classes. Finally, it concludes by adding some critical comments that could contribute to the future development of the discussion about social classes in Brazil.
PALAVRAS-CHAVE | Jessé Souza. Classes Sociais. Ralé. Batalhadores. Classes Superiores.
KEYWORD | Jessé Souza. Social Classes. Rabble; Hard Workers. Upper Classes. 


\section{INTRODUÇÃO}

m texto anterior (GOMES, 2019), sustentei que o atual projeto teórico de Jessé Souza pode ser reconduzido até sua guinada teórica anunciada no ano 2000, com a publicação do livro "Uma modernização seletiva" (SOUZA, 2000), e que de lá para cá os resultados desse projeto teórico podem ser divididos em três conjuntos principais: uma teoria da modernidade, uma teoria das classes sociais e uma teoria da relação entre ideias e práticas sociais, esta marcada pela crítica à leitura sobre o Brasil que se tornou dominante ao longo do século XX nas ciências sociais elaboradas em solo pátrio e pela crítica à relação entre essa leitura dominante e a autocompreensão da sociedade brasileira. No mencionado texto prévio, dediquei-me tanto à exposição detalhada da base teórica última em que se fundamentam aquelas duas primeiras teorias quanto à exposição específica e à crítica da teoria da modernidade, composta internamente por uma teoria da modernidade em geral, uma teoria da modernidade periférica e uma teoria da relação entre Brasil e modernidade. No presente texto, o objetivo é debruçar-me sobre a teoria das classes sociais, expondo-a de modo sistemático e oferecendo em face dela críticas que podem vir a contribuir para o importante debate em que ela se insere ${ }^{1}$.

Para o alcance desse objetivo, este artigo possui a seguinte estrutura: em primeiro lugar, resgato sucintamente os principais elementos da base teórica fundamental de Jessé Souza e relaciono essa base com sua teoria da modernidade. Nos três tópicos posteriores, abordo sua teoria das classes sociais enfatizando, nesta ordem, a "ralé", "os batalhadores", e as "classes superiores" - média e alta. Finalmente, levanto 1 Pretendo dedicar, de igual modo, um próximo texto ao terceiro dos três conjuntos principais de teses e argumentos que entendo comporem o projeto teórico de Jessé Souza - isto é, à sua teoria da relação entre ideias e práticas sociais. 
algumas críticas quanto a pontos que me parecem equivocados ou, quando menos, insuficientemente desenvolvidos.

Tanto quanto o texto anterior mencionado, este também pode ser lido como relatório parcial de uma das etapas de projeto de pesquisa individual que conduzo neste momento na instituição à qual me filio². Conforme a linha de investigação traçada em tal projeto e de acordo com os pressupostos metodológicos últimos que o informam, o propósito aqui não é dar conta do vasto debate que se tem construído em torno das teses de Jessé Souza, mas reconstruir sua argumentação por meio de uma crítica imanente a seus próprios textos. Esse caminho - pelo qual se pode ter acesso a questões sociológicas mais profundas retraçando-se uma certa "história da teoria sociológica, elaborada com intenção sistemática" (HABERMAS, 2010, p. 179) - permanece sendo um dos sentidos da categoria "reconstrução" como método crítico na obra de J. Habermas (HABERMAS, 2016)3.

\section{A TEORIA DA MODERNIDADE DE JESSÉ SOUZA: BREVE SÍNTESE ${ }^{4}$}

\subsection{Entre Charles Taylor e Pierre Bourdieu}

Desde 2003, com a publicação de "A construção social da subcidadania" (SOUZA, 2012a) ${ }^{5}$, os referenciais teóricos $2 \quad$ Faculdade de Direito da UFMG.

3 Conferir, por todos, o modo como J. Habermas explicita esse método (HABERMAS, 2010, p. 177-181) e dele se vale em sua "Teoria da Ação Comunicativa" (HABERMAS, 2010). Para um debate sobre as tensões em torno dessa categoria habermasiana, cf. NOBRE; REPA, 2012. Esse é um dos sentidos de "reconstrução" como método crítico na obra de J. Habermas (HABERMAS, 2016). Para um debate sobre as tensões em torno dessa categoria habermasiana, cf. NOBRE; REPA, 2012.

4 Para uma análise detalhada dos pontos tratados nesta seção, conferir GOMES, 2019.

5 Uma segunda edição desse livro, acrescida de um novo prefácio, foi 
precípuos de Jessé Souza aparentam estar consolidados: são eles as obras de C. Taylor e de P. Bourdieu. Sem dúvida, outras autoras e outros autores farão parte de seu projeto de investigação de ampla duração, como Nancy Fraser, Max Weber, Norbert Elias, Jürgen Habermas, Axel Honneth, Luc Boltanski e Ėve Chiapello, Bernard Lahire e Michel Foucault. Mas nenhuma delas e nenhum deles terá a centralidade de C. Taylor e de P. Bourdieu, sendo certo que é a partir de uma aproximação reciprocamente crítica entre as obras desses dois autores que o cerne do projeto teórico de Jessé Souza será construído.

O que interessa a esse projeto em C. Taylor é sua genealogia do que seria a "topografia moral do Ocidente". Esta seria caracterizada por dois princípios: princípio da interioridade e princípio da afirmação da vida cotidiana. Por afirmação da vida cotidiana entende-se uma contraposição frente à concepção da Antiguidade clássica, com sua exaltação da vida contemplativa em detrimento da vida prática (SOUZA, 2012a, p. 34). Diferentemente, catalisada quanto a esse aspecto sobretudo pela Reforma Protestante, a "topografia moral do Ocidente" viria redefinir aquela hierarquia, colocando no centro das atenções as esferas práticas do trabalho e da família, esferas das quais todas as pessoas, efetiva ou potencialmente, participam cotidianamente.

Quanto ao princípio da interioridade, por um lado, ele emerge como traço apto a distinguir os seres humanos das outras espécies de seres vivos: o acesso privilegiado a seu próprio interior seria a diferença basilar entre um ser humano e outros seres vivos, todos estes situados abaixo daquele numa escala de superioridade. Em outras palavras, a existência de algo para além do mero corpo, da mera corporeidade, a possibilidade de referência a algo como um interior, uma alma ou categoria semelhante, estaria no alicerce de uma hierarquização radical

lançada com o título de "A subcidadania brasileira: para entender o país além do jeitinho brasileiro" (SOUZA, 2018a). 
entre aquilo que é humano e aquilo que não é.

Por outro lado, esse princípio da interioridade desdobrase em dois princípios complementares e contraditórios, cada um com seu respectivo bem constitutivo. Assim, deriva do princípio da interioridade um ideal de controle racional das pulsões, paixões e instintos, controle realizado por um sujeito capaz de descolar-se de seu contexto de ação, colocando-se acima de si mesmo para decidir, com base numa razão calculadora, como agir. Noções como calculabilidade, raciocínio prospectivo, autocontrole e trabalho produtivo (SOUZA, 2012a, p. 35) estariam reunidas para forjar o que C. Taylor nomeará como "self pontual". Ao mesmo tempo, porém, deriva também do princípio da interioridade a valorização de um interior único em cada indivíduo, valorização que passa pela renomeação das paixões como sentimentos, sentimentos que, próprios de cada singularidade humana, podem e devem expressar-se no mundo. Paralelamente ao ideal do "self pontual", desenvolve-se, pois, o ideal do expressivismo. Aquele estaria ligado ao que há de universal entre os seres humanos, passando a referir-se à noção de dignidade; este, ao que há de singular em cada membro de uma humanidade compartilhada, referindo-se à noção de autenticidade. Nesse desdobramento complementar e contraditório do princípio da interioridade residiriam as fontes modernas de autoestima e reconhecimento social, ou seja, as fontes de onde seria possível extrair tanto a estima dos sujeitos por si mesmos quanto o seu reconhecimento pela sociedade.

A habilidade de C. Taylor no mapeamento da "topografia moral do Ocidente", entretanto, possuiria seus limites. Estes seriam visíveis sobremaneira na ausência de um questionamento aprofundado sobre o modo como essa hierarquia valorativa ocidental encontra-se imbricada com o complexo institucional mais robusto da modernidade - o Estado burocrático e o mercado de trocas capitalista - e com uma sociedade cindida em classes 
(SOUZA, 2012a, p. 73; 76). A essa limitação estaria ligada outra, nos termos da qual, segundo $\mathrm{C}$. Taylor, os problemas relacionados ao "self pontual" e à correspondente noção de dignidade estariam solucionados por meio de uma cidadania universalmente assegurada aos indivíduos, devendo a ênfase da teoria social recair nos problemas pertinentes ao ideal do expressivismo e à dimensão correspondente da autenticidade. Jessé Souza tem dúvidas quanto à adequação desse diagnóstico até mesmo para os países centrais, como a Europa, os Estados Unidos e o Canadá; e, por suposto, acha ainda mais inadequada sua extensão a países como o Brasil (SOUZA, 2012a, p. 7677). Como consequência, seria necessário complementar a abordagem tayloriana com a sociologia de P. Bourdieu.

Uma boa ponte para essa complementação é o conceito de "habitus". Ele se refere a um conjunto de disposições incorporadas, isto é, um conjunto de estruturas cognitivas e motivacionais que, inculcadas nos indivíduos ao longo do processo de socialização desde a infância, pré-configuram as possibilidades de cognição do entorno, de avaliação dos elementos que compõem esse entorno e de ação dentro desse entorno, sendo palpável, por exemplo, em hábitos alimentares, formas de sentar, de falar e de andar, corte de cabelo, escolha de vestuário, interesses esportivos ou culturais. Como disposições incorporadas, disposições tornadas corpo, essas estruturas cognitivas e motivacionais dão-se a compreender como se naturais fossem, fazendo opaca sua origem contingente (SOUZA, 2012a, p. 45-46).

Todavia, por um lado, a incorporação por meio do habitus relaciona-se diretamente com a dinâmica institucional da sociedade, uma vez que o complexo de instituições sociais fundamentais não levará a cabo o processo de reprodução continuada da sociedade senão por meio de prêmio e sanções, em um sentido sociológico desses termos, que selecionam tais 
e quais ações, inarredavelmente ligadas a tais e quais habitus. Por outro lado, o habitus específico de um indivíduo ou de um grupo de indivíduos varia de acordo com seu pertencimento de classe, o que traz consigo o problema da dominação de classe.

Para P. Bourdieu, em sociedades de elevada objetificação do capital como é a sociedade moderna, a dominação de classe tende a deixar de ter o caráter de uma dominação direta e violenta para assumir a forma de uma impessoalidade cujos mecanismos são mais sofisticados e mais difíceis de identificar. Nesse contexto, o conceito de classe social não pode aludir primariamente a uma determinada posição econômica, mas a um conjunto de práticas similares que possibilitam estratégias e consequências comuns mesmo diante da ausência de qualquer acordo refletido. Com isso, ganha destaque não tanto o capital propriamente econômico - embora, obviamente, ele não possa ser desconsiderado -, mas o "capital cultural", como soma de "capital educacional" e origem familiar (SOUZA, 2012a, p. 55). Se assim o é, a luta de classes adquire a fisionomia de uma "pelo poder de definir nos seus próprios termos (...) os esquemas classificatórios, em grande parte inconscientes e irrefletidos, que irão servir como orientação de comportamento a todas as classes sociais sob seu jugo" (SOUZA, 2012a, p. 58). Como consequência, as instituições centrais da sociedade moderna são internamente atravessadas por essa luta de classes, e as ações que selecionam com seus prêmios e sanções cotidianos correspondem sempre ao habitus de uma classe, ou de uma fração de classe, hegemônica.

Como o habitus é disposição incorporada e naturalizada em seu tornar-se corpo, as e os integrantes da classe - ou da fração de classe - dominante, que irão adquirindo o habitus hegemônico desde a tenra infância, terão sucesso assegurado de antemão naquelas instituições e, consequentemente, na sociedade em que em torno delas constituem-se os principais 
mecanismos de reprodução da vida social. Concomitantemente, as e os integrantes das classes dominadas estarão, desde antes, condenadas e condenados ao fracasso social. E, se toda a trama social desenrola-se a partir do habitus, esse fracasso social tenderá a ser interpretado, pelas classes e frações dominantes e dominadas, como tão natural quanto natural parece ser o habitus e tudo aquilo que o acompanha. A noção bourdieusiana de "distinção" destaca exatamente este ponto: a distinção justifica a dominação ao fincar a desigualdade em uma espécie de diferença "'merecida', correta e justa já que supostamente se basearia nos talentos inatos de seus possuidores" (SOUZA, 2012a, p. 58).

Por conseguinte, o aporte de P. Bourdieu oferece de maneira satisfatória a tematização da dinâmica institucional da sociedade e da luta de classes que nela se desenvolve, bem como esclarece sem margem para dúvidas que também nas sociedades de países como os europeus o problema da dignidade e da universalização da cidadania não está definitivamente resolvido. No entanto, também nesse aporte Jessé Souza apontará limitações. Elas se originariam na consideração descritiva do habitus das classes dominadas como meramente reativo ao das classes e frações dominantes (SOUZA, 2012a, p. 60-61), levando $P$. Bourdieu a não questionar a própria gênese das hierarquias sociais vigentes - como $\mathrm{C}$. Taylor faz - e conduzindo sua teoria a uma "radical contextualização" cujo sintoma mais forte seria a redução de toda análise social à disputa por poder e à lógica instrumental (SOUZA, 2012a, p. 85-87). Logo, faltaria a ele o recurso a critérios que, transcendentes aos conflitos de classe concretos, pudessem contribuir para a compreensão do pano de fundo no qual esses conflitos ocorrem. Por essa mesma razão, estaria fechada teoricamente a possibilidade de compreender qualquer mudança na sociedade positivamente como processo de aprendizagem, posto que as transformações sociais correspondentes seriam sempre nada mais do que a 
simples adequação de uma classe a certo habitus hegemônico.

Conhecidas as potencialidades e as insuficiências apontadas por Jessé Souza em ambos os autores, esvaise qualquer dificuldade em entender que sua base teórica é erguida, como ele assume expressamente, pela aproximação reciprocamente crítica entre os dois (SOUZA, 2012a, p. 87). É partindo dessa base que ele desenvolverá sua teoria da modernidade e sua teoria das classes sociais.

\subsection{A modernidade em geral, a modernidade periférica e a relação entre Brasil e modernidade}

Quanto à teoria da modernidade, ela, como dito na introdução do presente texto, pode ser dividida em uma teoria da modernidade em geral, uma teoria da modernidade especificamente periférica e uma teoria da relação entre Brasil e modernidade. No que diz respeito à modernidade em geral, sua arquitetura basilar estaria manifesta justamente na construção acima descrita, derivada de C. Taylor e P. Bourdieu: uma "topografia moral" caracterizada pelo princípio da afirmação da vida cotidiana e pelo princípio da interioridade, "topografia moral" essa que se encontra imbricada nas instituições centrais da vida social moderna e entrelaçada em uma continuada luta, simbolicamente mediada, entre classes constituídas por habitus distintos. Contudo, cada sociedade desenvolve-se concretamente apropriando-se de modo seletivo daquilo que seria um padrão estandardizado de modernidade, o que pode ser verificado empiricamente pelos caminhos diferentes seguidos, e pelos resultados diferentes alcançados na configuração social interna, por países como Estados Unidos, Alemanha e também o Brasil nos últimos séculos. Como conclusão, a passagem à modernidade é, por definição, aqui e alhures uma "modernização seletiva"6. Ou

$6 \quad$ É essa a tese-guia que justifica o título do livro que inaugura a 
seja, o Brasil não pode ser compreendido como um desvio em relação à modernidade, como uma negação da modernidade ou como um país de uma modernidade simplesmente superficial, epidérmica, inautêntica, tese sustentada em suas linhas gerais pelo conjunto de autores - como Sérgio Buarque de Holanda, Raimundo Faoro e Roberto DaMatta - que Jessé Souza vai englobar sob o rótulo de "sociologia da inautenticidade" (SOUZA, 2000 , p. 11); ao invés disso, o Brasil corresponderia a um desenvolvimento específico da modernidade, tal como o são os Estados Unidos, a Alemanha ou qualquer outro país moderno.

Não obstante essa arquitetura geral compartilhada por variados países, as consequências econômicas, sociais e políticas dispares de um mesmo conjunto de "princípios fundamentais de organização social" (SOUZA, 20012a, p. 77) requer uma distinção categorial ulterior entre dois blocos característicos de sociedades modernas: sociedades da modernidade central e sociedades da modernidade periférica. Em Jessé Souza, essa modernidade periférica estaria referida aos países da "nova periferia", não abrangendo a "velha periferia" formada por sociedades de culturas milenares como nos casos chinês e indiano. Nessa nova periferia, não se encontraria uma "visão de mundo articulada institucional e simbolicamente" (SOUZA, 20012a, p. 95) como nas sociedades da velha periferia; por outro lado, o "processo de lenta maturação e consolidação, permeada por guerras e conflitos de toda espécie" (SOUZA, 2012a, p. 93) que foi ao poucos forjando nas sociedades da modernidade central o ideário moderno reconstruído por $\mathrm{C}$. Taylor. O quadro resultante é o seguinte: em sociedades novo-periféricas, o ideário moderno chega de fora, junto com a introdução nelas das instituições modernas, como o Estado burocrático e o mercado de trocas capitalista. Ao chegarem de fora, elas não encontram a resistência que uma visão de mundo simbólica e institucionalmente articulada thes guinada teórica de Jessé Souza em 2000 (SOUZA, 2000). 
opôs inicialmente nas sociedades da velha periferia.

Isso não significa, porém, que inexistisse totalmente um contexto simbólico e institucional na nova periferia no momento em que as instituições da modernidade chegam a ela "de navio" (SOUZA, 2000, p. 245). Mas as articulações simbólicas e institucionais existentes seriam frágeis e condicionariam apenas negativamente as novas instituições, com suas novas práticas e seus novos valores. Para lidar com a forma como um novo ideário, encarnado em novas instituições, acomoda-se ao ideário previamente vigente, Jessé Souza recorre ao conceito tayloriano de "esquematização". Em relação à modernidade periférica, pois, poder-se-ia concluir que nela as instituições modernas são anteriores ao ideário moderno, ao complexo valorativo típico da modernidade, e que o frágil contexto simbólico e institucional prévio ao advento das instituições modernas influencia somente de forma negativa a esquematização do novo complexo valorativo, sua aclimatação ao novo território social.

A singularidade brasileira - singularidade entendida sempre como desenvolvimento próprio da modernidade, não como desvio dela - dentro da modernidade periférica deveria ser buscada, portanto, na esquematização sui generis entre as instituições da modernidade, com as práticas e o ideário correspondentes, e o contexto institucional e simbólico existente quando, no início do século XIX, Estado burocrático e mercado de trocas capitalista literalmente aportam nas praias da então colônia portuguesa.

Jessé Souza, relendo criticamente Gilberto Freyre, situará no tipo de familismo patriarcal escravista que tem lugar nas terras brasileiras desde a efetivação do projeto colonial português a chave para a compreensão dessa singularidade (SOUZA, 2012a, p. 112). A herança moura inscrita na escravidão que Portugal repetirá no Brasil permitia de partida uma ambiguidade entre distância radical e proximidade: em um dos limites, a escrava e 
o escravo eram assemelhados a coisas sobre as quais o senhor podia dispor; no limite oposto, não eram de todo raros os casos em que efetivamente passavam a integrar a família ampliada do senhor. Este, diante de uma pobre densidade institucional, não encontrava muitos limites à manifestação livre de seus impulsos e "desejos primários de sexo, agressividade, concupiscência ou avidez" (SOUZA, 2000, p. 227). Nesse cenário, fosse para galgar espaços dentro da lógica propiciada por aquela ambiguidade constitutiva das relações de escravidão, fosse para evitar a efetivação de uma crueldade sempre virtualmente presente, desenrolava-se uma espécie de acoplamento sadomasoquista como traço social: a identificação com as vontades e os valores do senhor, mesmo quando pudesse significar alguma dose de dor e sofrimento, garantia uma dose menor do que aquela que poderia explodir a qualquer momento como resposta à contrariedade a essa vontade (SOUZA, 2012a, p. 105).

Logo, se desde a chegada das instituições modernas à sociedade do que viria a ser o Brasil independente é possível falar de um único "código valorativo dominante: o código do individualismo ocidental" (SOUZA, 2000, p. 254, destaques do original), a esquematização desse código valorativo pelo familismo patriarcal escravista instaurará uma nova dinâmica social em que o acesso aos "bens culturais que são aceitos ou que passam a ser tendencialmente aceitos pela enorme maioria da população como os valores dominantes da sociedade como um todo" (SOUZA, 2000, p. 255, destaques do original) não se dá universalmente, derivando do acesso diferencial a esses bens uma nova forma de hierarquização social. Se o senhor

tem o desafio de, bem ou mal, adaptar-se aos novos tempos. O escravo, esse vai ser abandonado e ficará desprovido de acesso às benesses do novo sistema que se institucionaliza a partir de então. 
Quem ocupa os novos empregos abertos pelo desenvolvimento de manufaturas e maquinofaturas é o mulato e depois o imigrante. O negro, vítima de preconceito e do seu próprio abandono, não teve nem terá acesso mais tarde ao lado menos sombrio dos novos tempos (SOUZA, 2000, p. 265).

Estava prefigurada, dessa maneira, a possibilidade social de existência de todo um contingente populacional que, como herança de uma sociedade forjada na escravidão, de um lado tenderia a desenvolver uma identificação subalterna com os valores e interesses das classes dominantes, enquanto, de outro lado, a qualquer tempo poderia ter negado a ele o próprio atributo básico da condição da humanidade, o próprio reconhecimento como gente, sendo não mais do que "subgente": em outras palavras, no movimento mesmo da modernização da sociedade brasileira, vai sendo constituída, como desdobramento dessa modernização e não como negação dela, uma classe social inteira à qual Jessé Souza chamará, em tom assumidamente provocativo, de ralé (SOUZA, 2011, p. 21). É exatamente neste ponto que sua teoria da modernidade cruza-se com sua teoria das classes sociais.

\section{A RALÉ ESTRUTURAL}

De uma perspectiva histórica, a ralé origina-se da população de escravos e de escravas e da figura do "dependente formalmente livre" tal qual estudada por Maria Sylvia de Carvalho Franco (FRANCO, 1997). Este último, embora distinto da população escrava, decorria igualmente da instituição social da escravidão: "A agricultura mercantil baseada na escravidão simultaneamente abria espaço para sua existência e os deixava sem razão de ser" (SOUZA, 2012a, p. 121). Com isso, não 
sendo senhor nem escravo, constituía-se como um "despossuído formalmente livre, cuja única chance de sobrevivência era ocupar funções nas franjas do sistema como um todo" (SOUZA, 2012a, p. 121). Nesse grupo, incluíam-se pessoas variadas, que desempenhavam funções as mais diversas, merecendo destaque o "agregado" rural ou urbano, fosse ele o tropeiro, o vendeiro, o sitiante ou o "cabra" ou "capanga" responsável pela proteção armada do senhor. Em todos esses casos, o traço comum era o laço de dependência em relação ao senhorio, laço que, se não se confundia com a escravidão, enredava o indivíduo formalmente livre em uma teia complexa de troca de favores e proteção no interior da qual havia um elevado grau de heteronomia entre duas figuras que, do ponto de vista apenas formal, eram consideradas iguais (SOUZA, 2012a, p. 125). É essa configuração social que permite Jessé Souza englobar numa única classe escravos e escravas, de um lado, e dependentes formalmente livres, de outro:

O aspecto mais interessante das visões do escravo na "escravidão muçulmana" (...) e do dependente formalmente livre (...) é sua extraordinária contiguidade. Ambos são obrigados, através de processos e precondições sociais distintos, a assumirem posições quase que intercambiáveis. Aos dois é comum o fechamento do próprio horizonte de percepção dos seus interesses e a subordinação, como se fosse uma eleição advinda de escolha autônoma, aos interesses e desejos do senhor. Ambos irão formar a "ralé" dos imprestáveis e inadaptados ao novo sistema impessoal que chega de fora para dentro (...). (SOUZA, 2012a, p. 128) 
Nessa explicitação da origem histórica da ralé já se vislumbra sua definição categorial: as pessoas que hoje encarnam a herança daqueles dois grupos históricos podem ser compreendidas como sendo pertencentes a uma classe cujo habitus característico as torna imprestáveis e inadaptadas perante o código valorativo dominante na modernidade e perante as instituições que lhe encarnam e, por meio de um complexo sistema de estímulos, dão a ele continuidade na reprodução cotidiana da vida social.

Sendo o mercado de trocas capitalista e o Estado burocrático as instituições fundamentais dessa modernidade, "o capital cultural, sob a forma de conhecimento técnico e escolar" (SOUZA, 2011, p. 21), assume uma centralidade inédita na disputa simbólica por recursos escassos dentro das sociedades modernas, ainda que o capital econômico não perca sua relevância e continue, por suposto, relacionado ao próprio capital cultural. Por conseguinte, as classes que ocupam a posição dominante nessas sociedades se caracterizam pela posse diferencial desses dois capitais, sejam as classes médias, historicamente desenvolvidas pela apropriação de capital cultural, sejam as classes altas, em geral marcadas pela apropriação hereditária de capital econômico, ao qual se soma certa porção de capital cultural.

O problema é que, além dessas classes, o processo de modernização brasileiro produz também

uma classe inteira de indivíduos, não só sem capital cultural nem econômico em qualquer medida significativa, mas desprovida, esse é o aspecto fundamental, das precondições sociais, morais e culturais que permitem essa apropriação. (SOUZA, 2011 , p. 21, destaques do original) 
Ou seja, a ralé não só é desprovida de capital econômico e cultural em quantidade relevante, sendo também carente das precondições que poderiam ensejar sua apropriação no transcurso do tempo. Mas o que seriam essas precondições? Jessé Souza destaca o papel de habilidades como "[d]isciplina, capacidade de concentração, pensamento prospectivo (que enseja o cálculo e a percepção da vida como um afazer 'racional')" (SOUZA, 2011, p. 23). Tais habilidades corresponderiam a necessidades funcionais tanto do mercado de trocas quanto do Estado burocrático, de modo que a posse delas assegura tendencialmente o sucesso na dinâmica social promovida por essas instituições e, consequentemente, nas lutas de classes que ocorrem em torno delas. Constitutivas do habitus de classes que, por meio dele, reproduzem-se como classes dominantes, essas habilidades tendem a ser percebidas como se fossem inatas, naturais a qualquer indivíduo, independentes da pertença de classe. Todavia, Jessé Souza procura mostrar como elas são transmitidas no cotidiano de uma socialização familiar específica, sobretudo "por mecanismos de identificação afetiva por meio de exemplos cotidianos" (SOUZA, 2011, p. 23), e, em razão disso, precisam ser compreendidas como uma aquisição dos indivíduos ao longo de um processo de formação que tem início desde a tenra infância e que depende radicalmente de um arranjo familiar não disponível na ralé: em suma, trata-se de habilidades cuja posse encontra-se internamente vinculada ao pertencimento a classes específicas.

Se a ralé não possui capital econômico nem cultural em medida significativa, se ela também não possui as precondições que, assegurando sucesso na competição travada em volta do mercado e do Estado, poderiam permitir a obtenção desses capitais no transcurso histórico, se essas precondições, por fim, são transmitidas num tipo de socialização familiar ausente na ralé, a conclusão impõe-se: a ralé tende a reproduzir-se como ralé 
no tempo, não sendo sua existência uma contingência histórica mutável com a mudança das conjunturas. Ao contrário, a ralé é, como classe, uma ralé estrutural.

Em decorrência de sua conformação como classe, a ralé diferencia-se do conceito marxista de lumpemproletariado, posto que este "podia funcionar como exército de reserva, porque podia ser empregado em épocas de crescimento econômico ao lado da força de trabalho ativa" (SOUZA, 2011, p. 23). Diferentemente, no cenário contemporâneo em que o capitalismo incorpora elevado conhecimento técnico concomitantemente a uma articulação de seus processos produtivos fortemente marcada por disciplina, concentração e capacidade de prospecção - isto é, habilidades ligadas a certa aprendizagem de uma relação paciente e projetiva com o tempo -, a ralé, não obstante fases de acentuada expansão da atividade econômica, simplesmente não consegue ser absorvida pelas atividades formais típicas do âmbito do mercado - não se colocando também como apta a ocupar os cargos formais minimamente relevantes da estrutura do Estado e de sua administração pública.

Assim, à ralé são deixados apenas os postos funcionais que padecem em geral de qualquer segurança, estabilidade e possibilidade de realização social. São ocupações como emprego doméstico e guarda e lavagem de carros na rua, ou, no limite, como a prostituição e a delinquência. $O$ que há de comum em todas elas é que para seu exercício não é necessária a incorporação de significativas habilidades específicas. Basta, em regra, o corpo: "a ralé se reproduz como mero corpo" (SOUZA, 2011, p. 23).

Nesse "reproduzir-se como mero corpo" da ralé estrutural reside uma das consequências existencialmente mais dramáticas para os indivíduos que compõem essa classe. Se, conforme C. Taylor, os princípios da afirmação da vida cotidiana e da interioridade definem a "topografia moral do Ocidente" moderno, 
e se o princípio da interioridade desdobra-se em "self pontual" e expressivismo e nas noções correspondentes de dignidade e autenticidade, sendo essas as duas fontes possíveis da autoestima e do reconhecimento, a ralé tem a ela tudo isso negado. Como "mero corpo", a ralé estaria, dada a clivagem posta pelo binômio constituído pelo princípio da interioridade - corpo de um lado, alma de outro; pulsões, instintos e paixões de um lado, razão e sentimentos de outro - no polo oposto àquele que reuniria em si toda a humanidade em contraposição aos, e acima dos, demais seres vivos.

A possibilidade de alcançar autoestima e reconhecimento por meio da manifestação de um vida interior autêntica inexiste na medida em que o circuito das necessidades mais elementares dificulta qualquer autonomização não funcional da estética, estando o gosto da ralé destinado a ser desprezado socialmente em face do gosto ${ }^{7}$ refinado das classes médias e altas - o que vale tanto para a gastronomia e a música quanto para o ideal de vida boa e a ritualização do amor erótico. Mas, ainda mais grave, é o fato de que nem mesmo a possibilidade de um reconhecimento basilar fundado na noção de dignidade e efetivado por meio de uma cidadania tendencialmente universalizada encontra-se ao alcance de uma ralé que não corresponde ao ideário do "self pontual". Se o reconhecimento de si, por si mesmo e pelos outros, como humano está, nas sociedades modernas, fincado nessas duas fontes, estando ambas indisponíveis à ralé o que ocorre socialmente é que também o atributo da humanidade está em certo sentido - no sentido da efetividade social desse atributo indisponível para ela:

É por conta disso que a "ralé" estrutural brasileira, como a classe do "corpo" por excelência, pela

7 E o gosto "não é apenas uma dimensão estética, mas, antes de tudo, uma dimensão moral" (SOUZA, 2012b, p. 49). 
ausência de incorporação em qualquer medida significativa dos pressupostos emocionais $\mathrm{e}$ morais tanto da dignidade do agente racional disciplina, autocontrole, pensamento prospectivo, que significam a "alma" ou a "mente" - quanto da "expressividade" do sujeito diferenciado - o culto à "sensibilidade" que é a outra forma de se definir "alma" e "mente" - é uma classe desprezada e não reconhecida. (SOUZA, 2011, p. 398)

É gente que é percebida socialmente como menos gente - como subgente, subcidadãos - e que, portanto, é formada por pessoas cujo sofrimento, dor e, no extremo, a própria morte não importa, pois, não considerada como gente na plenitude do sentido, seu sofrimento, sua dor e sua morte cotidianos são socialmente invisibilizados e naturalizados.

Dois caminhos poderiam ser intuitivamente pensados como formas de resistência da ralé diante da construção social reiterada de sua condição de subgente. Um primeiro seria uma solidariedade capaz de fortalecer coletivamente as pessoas dessa classe e fazer frente, por meio de laços e redes de suporte recíproco cotidiano, às mazelas socialmente impostas. Quanto a isso, Jessé Souza identifica nos seus estudos empíricos que a potencialidade da ralé para encaminhar-se em direção a práticas ligadas à delinquência produz, internamente a ela, uma cisão entre pessoas vistas como tendo escolhido o caminho certo e pessoas vistas como tendo escolhido o caminho errado, entre "ralé honesta" e "ralé delinquente". Sem a compreensão do condicionamento social de sua situação como classe, também a ralé cede ao discurso que, obscurecendo a gênese das desigualdades sociais fundadas no habitus, legitima essas desigualdades como se decorressem de fatores naturais e, a partir deles, de escolhas livres à disposição de todo e qualquer 
indivíduo. Em outros termos, "[é] a própria solidariedade da classe mais oprimida, enquanto classe, em todas as dimensões, que é comprometida" (SOUZA, 2011, p. 425).

O outro caminho seria o do engajamento político. Em relação a este, entretanto, o desconhecimento das condicionantes sociais de sua situação como classe tenderia a gerar na ralé tanto a aceitação dessa situação como algo merecido quanto a busca por soluções não articuladas politicamente, soluções "mágicas", sejam elas esperanças de mudanças milagrosas da noite para o dia depositadas em formas de exercício religioso ou revoltas pessoalizadas - atos levados a termo individualmente e contra pessoas específicas. A conclusão de Jessé Souza é no sentido de que a ralé seria caracterizada não somente pela miséria moral e existencial, mas também pela passividade política (SOUZA, 2011, p. 410-419).

Não restariam, então, alternativas? O final do livro dedicado exclusivamente ao estudo da ralé estrutural é, no mínimo, impactante (SOUZA, 2011, p. 419-431): Jessé Souza opõe-se veementemente a qualquer procura por soluções de curto prazo, entendidas por ele como soluções "mágicas" profundamente equivocadas, e critica inclusive a pergunta por soluções, pois trariam consigo implicitamente a expectativa de encontrar naquelas soluções "mágicas" a resposta. Ao contrário, sustenta ele que a única alternativa possível seria a de uma aprendizagem social de longo prazo, no decurso da qual a sociedade brasileira pudesse compreender a necessidade de extensão a todas as classes sociais daquelas condições mínimas que asseguram dignidade e efetivam a cidadania - extensão essa que seria o traço diferenciador por excelência das sociedades da modernidade central (SOUZA, 2012a, p. 128). 


\section{OS BATALHADORES BRASILEIROS}

No livro imediatamente posterior àquele dedicado à ralé, "Batalhadores" (SOUZA, 2012b) é o nome que Jessé Souza cunhará para identificar uma parcela da população que vinha sendo denominada, e ainda hoje o é em escala significativa, como nova classe média. Esse fenômeno, segundo as explicações dominantes, derivaria em linhas gerais da estabilização econômica alcançada nos governos FHC e das políticas de inclusão conduzidas, a partir dessa base, pelos governos Lula e Dilma. A conjugação desses fatores teria viabilizado um aumento tanto da renda quanto do padrão de consumo das camadas mais baixas da pirâmide da distribuição econômica, o que tornaria possível falar do surgimento de uma nova classe média.

A escolha, da parte de Jessé Souza, de um outro conceito para identificar esse fenômeno tem a finalidade tanto de marcar a diferença dessa classe em relação às classes médias tradicionais quanto de chamar atenção para o equívoco nos pressupostos de análise que levam à conclusão segundo a qual estar-se-ia diante de uma nova classe média.

Quanto aos pressupostos de análise, um primeiro problema seria o conceito mesmo de classe, que, como abordado acima, a partir de P. Bourdieu não poderia ser reduzida a uma questão apenas econômica, muito menos a uma questão meramente de renda e consumo (SOUZA, 2012b, p. 19-26). Em segundo lugar, a emergência dessa nova classe não poderia ser analisada somente em um marco interno ao Brasil. As condições de possibilidade de seu surgimento precisariam ser situadas também dentro do conjunto de transformações que atinge o capitalismo global no final do século XX (SOUZA, 2012b, p. 26-39). O traço fundamental dessas transformações é a financeirização do capital. Com ela, tem lugar toda uma reestruturação da ordem econômica. 
Por um lado, a base tipicamente fordista do chão de fábrica perde espaço, posto que o capital retira-se progressivamente da esfera da produção, pulverização esta tanto em território global quanto, internamente a um mesmo território nacional, em uma série de pequenos empreendimentos que passam a assumir a tarefa arriscada de produzir, mantendo ao capital a segurança do recebimento da remuneração sob a forma de juros. Por outro lado, a sociedade erguida sobre a base fordista convivera com críticas de matiz moral e cultural desde a década de 1960, críticas quanto à homogeneização massificante dessa sociedade e à correspondente falta de espaço para o desenvolvimento da diferença e da liberdade criativa. O capitalismo reconfigurado nas últimas décadas do século passado teria conseguido apropriar-se dessas críticas e fazer delas o mote de seu novo desenvolvimento - o que, em termos taylorianos, significa que o capitalismo soube explorar bem um dos pilares das fontes morais modernas de autoestima e reconhecimento social, vindo a pretender ser uma espécie de capitalismo expressivista.

Assim, uma nova classe - sem dúvida também propulsionada pela política interna ao país - pôde ocupar o espaço deixado pelo capital que se retira em elevada monta do envolvimento direto com a atividade produtiva, sendo concomitantemente estimulada pelo ideário generalizado do empreendedor, do "seja patrão de si".

Como consequência, é marcante na classe dos batalhadores a presença de pequenos empreendimentos, muito deles de base familiar. Mas isso não define a classe: nela também estão presentes pequenos empreendimentos em que $o$ trabalho é controlado segundo princípios fordistas, tanto quanto empregadas e empregados que precisam adequar-se à dinâmica flexível do novo capitalismo - como operadoras e operadores de telemarketing -, dentre outras ocupações. A regra, na verdade, é a heterogeneidade, sendo que o elemento que dá liga consiste em 
que "a alocação e o regime de trabalho são realizados de modo novo, de modo a ajustá-los às novas demandas de valorização ampliada do capital financeiro" (SOUZA, 2012b, p. 56).

Por conseguinte, não é difícil vislumbrar o quanto a heterogeneidade das ocupações internas aos batalhadores encontra-se distante das proteções trabalhistas geradas ao longo das décadas e relativamente generalizadas no contexto fordista: como cara de uma moeda cuja coroa é o ajuste às demandas de valorização do capital financeiro, também caracteriza essa nova classe uma "distorção e precarização das condições de trabalho (...), encoberta e distorcida como triunfo da criatividade, da ousadia, da coragem e da liberdade" (SOUZA, 2012b, p. 54).

Delineada dessa maneira a classe dos batalhadores, contudo, não se tem ainda sua definição conceitual adequada. Esta passa pela subsequente diferenciação entre os batalhadores e, de um lado, as classes médias tradicionais e, de outro lado, a ralé.

Sobre a diferença entre batalhadores e classes médias tradicionais, aqueles não possuem o acesso diferencial aos capitais econômico e, principalmente, cultural que caracteriza estas. Ademais, falta-lhes o gosto, aquele elemento de distinção que antecede as chances de vitória em uma luta de classes mediada simbolicamente. Ao invés disso,

essa classe conseguiu seu lugar ao sol à custa de extraordinário esforço: à sua capacidade de resistir ao cansaço de vários empregos e turnos de trabalho, à dupla jornada na escola e no trabalho, à extraordinária capacidade de poupança e de resistência ao consumo imediato e, tão ou mais importante que tudo que foi dito, a uma extraordinária crença em si mesmo e no próprio trabalho. (SOUZA, 2012b, p. 50) 
Quanto à diferença frente à ralé, um primeiro ponto a ser destacado é, antes, a semelhança: os batalhadores consistem numa "classe quase tão esquecida e estigmatizada quanto a própria 'ralé"' (SOUZA, 2012b, p. 47). Todavia, essa nova classe teria conseguido "internalizar e in-corporar disposições de crer e agir que lhe garantiram um novo lugar na dimensão produtiva do novo capitalismo financeiro" (SOUZA, 2012b, p. 48). Com isso, o integrante da classe dos batalhadores, "ao contrário da ralé (...), é reconhecido como membro útil à sociedade e pode criar uma narrativa de sucesso relativo para sua trajetória pessoal" (SOUZA, 2012b, p. 52) - o que não desfaz o fato de sua inclusão continuar sendo uma inclusão subordinada.

Mas o que permitiria a essa parcela da população, na qual se encontra inclusive certa "elite da ralé" (SOUZA, 2012b, p. 47), a aquisição dessas características, a incorporação de um habitus no qual estão presentes aqueles pressupostos emocionais e morais como disciplina, autocontrole e pensamento prospectivo, indispensáveis ao sucesso numa sociedade institucionalmente estruturada ao redor de Estado burocrático e mercado de trocas capitalista? Para Jessé Souza, um elemento fundamental para a resposta a essa pergunta seria o "capital familiar":

o que parece estar em jogo na ascensão social dessa classe é a transmissão de exemplos e valores do trabalho duro e continuado, mesmo em condições sociais muito adversas. Se o capital econômico transmitido é mínimo, e o capital cultural e escolar comparativamente baixo em relação às classes superiores, média e alta, a maior parte dos batalhadores entrevistados, por outro lado, possuem família estruturada, com a incorporação dos papéis familiares tradicionais de pais e filhos bem desenvolvidos e atualizados. 
Essa é uma distinção fundamental em relação às famílias da "ralé" (...). (SOUZA, 2012b, p. 50)

Outro elemento residiria na "capacidade associativa direta ou indiretamente estimulada pelo pertencimento a comunidades religiosas" (SOUZA, 2012b, p. 366). Jessé Souza oscila entre atribuir primazia a um ou a outro desses dois elementos, mas, como quer que seja, neles estaria a explicação crucial para a diferença entre as classes da ralé e dos batalhadores.

Compreendidas as especificidades dos batalhadores como classe, e sabendo que essa classe abrange inclusive integrantes da ralé - de uma "elite da ralé" -, o diagnóstico anterior acerca dessa outra classe acaba revelando-se equivocado:

A atual pesquisa permitiu, inclusive, corrigir algumas perspectivas que desenvolvemos no estudo anterior. Como o que nos interessava no livro anterior era apontar os mecanismos que possibilitavam a "reprodução" indefinida da "ralé" no tempo, nos concentramos na identificação dos fatores que a mantinham no mesmo lugar. Nesta pesquisa, fomos confrontados também com outra realidade, que nos mostrou, sobejamente, que mesmo a "ralé" não é estática, mas está, ao contrário, em constante movimento. (SOUZA, 2012b, p. 368)

$\mathrm{E}$, tendo sido parcialmente corrigido o diagnóstico anterior, a posição sobre as soluções de mudança, sobre as alternativas de transformação social, também são matizadas, posto que passam a ser destacadas "políticas públicas compensatórias abrindo oportunidades de estudo e de inserção no mercado mais competitivo", capazes de engendrar "formas mais inclusivas e 
justas de desenvolvimento do capitalismo que são perfeitamente possíveis e compatíveis com o exercício de garantias liberais para a ação individual" (SOUZA, 2012b, p. 368).

\section{AS CLASSES SUPERIORES}

Os estudos de Jessé Souza quanto às classes superiores, aquelas que ocupam posição dominante na luta de classes contemporânea simbolicamente mediada, encontravam-se em um estado assumidamente preliminar de desenvolvimento até o fim de 2018, momento de publicação do livro "A classe média no espelho: sua história, seus sonhos e ilusões, sua realidade" (SOUZA, 2018b). Antes dessa publicação, a apresentação dos primeiros resultados dos estudos sobre essas classes havia aparecido apenas de modo bastante sintético no livro "A elite do atraso: da escravidão à Lava Jato" (SOUZA, 2017).

Um primeiro elemento importante a ser retomado para a compreensão de tais classes é aquilo que as distingue como classes dominantes: a posse de capital econômico e capital cultural. $\mathrm{Na}$ classe alta, o elemento que se mostra axial é o capital econômico transmitido em regra por herança patrimonial, ao qual se soma o capital cultural adquirido em doses variadas. $\mathrm{Na}$ classe média e em suas frações, ao contrário, a ênfase recai no capital cultural, não sendo o capital econômico hereditário ausente, mas desempenhando um papel menos relevante do que aquele desempenhado na classe alta.

A posse sobretudo do capital cultural está diretamente ligada ao gosto e a possibilidade da distinção social. Como essa distinção é fundada no habitus e como o habitus dominante entrelaça-se com a dinâmica institucional da sociedade e com seus complexos mecanismos de prêmios e sanções, as e os integrantes das classes superiores têm de antemão assegurado tendencialmente o sucesso nas condições de competição da 
sociedade moderna. A um só tempo, como o habitus, disposição incorporada, é a opacidade de sua própria gênese, esse sucesso pode ser interpretado socialmente, inclusive pelas classes dominadas, como sucesso merecido, sucesso que, meritocraticamente estabelecido, justificaria as desigualdades que se mantêm socialmente. A consequência é a naturalização e a invisibilidade da desigualdade mesmo em um país onde ela atinge patamares gritantes, como é o caso do Brasil.

Especificamente quanto à classe média, naquela primeira apresentação dos resultados de suas pesquisas (SOUZA, 2017) Jessé Souza afirma ser possível mapear quatros nichos ou frações na classe média brasileira: fração protofascista, fração liberal, fração expressivista e fração crítica. Para chegar a esse quadro, as duas principais balizas utilizadas foram "a noção de moralidade mais ou menos abrangente e mais ou menos refletida, e a forma como se percebe as outras classes sociais" (SOUZA, 2017, p. 172-173). Quantitativamente, a maior delas seria a fração liberal, com $35 \%$ do total de integrantes das classes médias, seguida pela fração protofascista, com cerca de $30 \%$, pela fração expressivista, com algo em torno de $20 \%$, e, finalmente, pelos $15 \%$ da fração crítica (SOUZA, 2017, p. 174).

No que diz respeito à caracterização dessas frações de classe, o fator decisivo para a compreensão de sua heterogeneidade seria "o tipo de capital cultural diferencial que é apropriado seletivamente pelas respectivas frações, construído pelas socializações familiar e escolar distintas" (SOUZA, 2017, p. 173). As frações liberal e protofascista corresponderiam à classe média típica "do conhecimento técnico, ou seja, daquele tipo de conhecimento que serve diretamente às necessidades do capital e sua reprodução e de menor contribuição para uma transformação da própria personalidade" (SOUZA, 2017, p. 177). São as frações mais suscetíveis à grande mídia e ao discurso homogeneizador por ela construído em estreita interdependência 
com as visões de mundo difusamente já presentes no seio dessas mesmas frações. O capital cultural que privilegiam é aquele do tipo afirmativo da ordem social vigente, capaz de transmitir a essas frações de classe a sensação de que se está no caminho correto, correção derivada simplesmente de se poder acreditar que é esse o caminho da maioria. Em razão disso, são também as frações do moralismo, da "boa consciência das certezas compartilhadas" (SOUZA, 2017, p. 179).

Comungando essas características mais gerais, a diferença entre a fração liberal e a protofascista fica, em princípio, por conta do maior ou menor apego ao ideário democrático. Para a fração liberal, "os rituais de convivência democrática são constitutivos" (SOUZA, 2017, p. 179); para a fração protofascista, não. Ela expressa continuamente seu ódio e seu ressentimento em relação às classes dominadas, e se orgulha de fazê-lo entendendo sua postura como sincera e ousada. Não tendo aprendido o caminho da autocrítica - pois o capital cultural legítimo para ela é apenas aquele que confirma seus próprios pontos de vista -, ela possui uma sensibilidade elevada a qualquer crítica recebida, em geral seguida de uma resposta potencialmente violenta (SOUZA, 2017, p. 179-180).

A fração expressivista é a que melhor encarna a defesa do pilar correspondente na "topografia moral do Ocidente". O foco da constituição da personalidade de suas e de seus integrantes, bem como do posicionamento político e moral que assumem no mundo, está ligado à preservação do meio ambiente, à proteção das minorias identitárias, à sustentabilidade e à responsabilidade social de empresas. Sua postura expressivista, entretanto, não viria acompanhada de "qualquer crítica social que envolva efetiva distribuição de riqueza e de poder" (SOUZA, 2017, p. 175), motivo pelo qual Jessé Souza opta por chamá-la de "classe média de Oslo": 
Tudo se dá como se esse pessoal bem-intencionado morasse em Oslo e tivesse apenas relações com seus amigos de Copenhague e Estocolmo, acreditando, ao fim e ao cabo, que mora na Escandinávia e não no Brasil. Para um sueco que efetivamente resolveu os problemas centrais de injustiça social e distribuição de riquezas, não é estranho que se dedique à preservação de espécies raras e faça dessa luta sua atuação política principal. Que um brasileiro faça o mesmo e se esqueça da sorte de tantos seres humanos tão perto dele é apenas compreensível se ele os torna invisíveis (SOUZA, 2017, p. 176).

Finalmente, a fração crítica seria assim denominada não por causa de uma posição política particular, mas por sua atitude em face do mundo social. Este, para ela, não é tomado como algo dado, mas algo construído. Logo, requer não adaptação, mas engajamento na continuação do processo de construção e reconstrução desse mundo. Essa atitude ativa frente ao mundo torna essa fração consciente das dificuldades de se alcançarem concretamente formas de liberdade pessoal e social, autonomia real, numa sociedade perversa e repressiva como a brasileira. Não obstante, essa trama de dificuldades em que ela se envolve faz dela também, como as outras frações da classe média, repleta de contradições.

Para além dessas diferenciações, a classe média como um todo seria marcada por sua busca para distinguir-se tanto das classes dominadas, como a ralé e os batalhadores, quanto da classe alta. Em relação a esta - a "elite do dinheiro", segundo Jessé Souza -, a classe média procuraria justificar-se com o moralismo, embora este seja, como visto, mais forte nas frações liberal e protofascista. $\mathrm{O}$ argumento, em linhas gerais, desse 
moralismo que atravessa a classe está intimamente ligado ao tema da meritocracia: sem a herança de um capital econômico significativo de partida, a classe média não só não se envolveria nos grandes escândalos de corrupção, mas mereceria tudo o que tem em razão de seu esforço pessoal. Em outras palavras, ela poderia vangloriar-se da "certeza de sua perfeição moral" (SOUZA, 2017, p. 168), independentemente do modo como se relaciona com as classes mais baixas.

Quanto a essas classes mais baixas, a buscar por distinguir-se passa pela noção de populismo. Para Jessé Souza, nessa noção - tão cara à teoria social dominante no Brasil ao longo do século XX - estariam embutidos "um ódio e um desprezo cevados secularmente pelo povo" como talvez a "nossa maior herança intocada da escravidão" (SOUZA, 2017, p. 169). Por um lado, a participação política das camadas mais pobres da sociedade tende a ser criticada, pois sua atuação é inferior e baseada apenas nos interesses mais imediatos - no limite, aqueles "do estômago" (SOUZA, 2012b, p. 199-255). Por outro lado, qualquer atuação governamental em seu benefício, ainda quando apoiada nos mandamentos constitucionais e nos modelos de bem-estar social que fizeram da desejada Europa ser o que é, são de pronto deslegitimados como meros projetos clientelistas.

O livro de 2018 traz uma abordagem algo diferente daquela apresentação inicial de 2017. Assim, a ideia de quatro nichos ou frações de classe perde centralidade, aparecendo de modo diluído ao longo do novo livro. Em seu lugar, uma outra cisão é destacada: aquela entre a "alta classe média" e a "massa da classe média":

Passei a atentar menos para os cortes horizontais das frações das classes médias, ainda que sejam relevantes para a análise, e enfocar mais as distinções verticais, que permitem diferenciar a 
"alta classe média" da "massa da classe média", ou seja, a hierarquia específica no interior do próprio segmento social. (SOUZA, 2018b, p. 21)

A alta classe média seria composta pelas pessoas que exercem "a função de comando da sociedade em todos os níveis, mas em nome de uma ínfima elite de proprietários efetivos" (SOUZA, 2018b, p. 21). Ocupando postos muito bem remunerados - remuneração que, no contexto do capitalismo financeiro contemporâneo, deixa progressivamente de ser etiquetada como "salário" para receber rótulos que indicam "participação nos lucros" (SOUZA, 2018b, p. 205), isto é, participação nos frutos do sucesso da empresa -, essa classe é marcada pela "ilusão objetiva" (SOUZA, 2018b, p. 21) de ser ela mesma a elite da sociedade, o que dificulta a percepção da especificidade de seu lugar social e a adoção de uma postura reflexiva e crítica, sendo reiteradamente cativa da visão de mundo e da posição político-ideológica típica da classe de proprietários efetivos, isto é, uma visão liberal avessa a qualquer restrição aos mecanismos de lucratividade financeira e a qualquer instrumento de compensação social. Se observada segundo os parâmetros de renda, essa classe seria o equivalente aos estratos mais elevados da classe $A$, que ela dividiria precisamente com o ínfimo conjunto de proprietários efetivos.

A massa da classe média corresponderia ao que se costuma chamar de "classe média baixa ou média", abrangendo, em termos de renda, "a maioria da classe A e a totalidade da classe B" (SOUZA, 2018b, p. 21-22). Responsável por funções de gestão intermediária no mercado ou no Estado (SOUZA, 2018b, p. 131), não há nela a possibilidade de uma identificação objetiva com as classes altas, a elite social. Objetivamente mais próxima das classes baixas - com padrões de renda que muitas vezes não a diferenciam dos "batalhadores" - a compreensão que tem de si, 
de seu lugar na sociedade e da própria sociedade é complexa: "espremida entre as classes altas e as classes populares, vai refletir as angústias dessa posição ambígua" (SOUZA, 2018b, p. 131). Assim, é possível encontrar nela tanto apoio a projetos de atuação estatal voltados para o desenvolvimento e a redução das desigualdades quanto ressonância de ideais autoritários e, no limite, fascistas (SOUZA, 2018b, p. 131-133), estes em regra agravados pelo risco de rebaixamento social e pelo medo da consequente proletarização.

De um ponto de vista quantitativo, a massa da classe média teria um contingente de entre $15 \%$ e $18 \%$ da população brasileira, enquanto a alta classe média não abrigaria mais do que $2 \%$ dessa população, seguida da "fração de grandes proprietários, a 'elite real', ainda bem menor e mais restrita" (SOUZA, 2018b, p. 22).

A justificativa para destacar essa cisão entre alta classe média e massa da classe média, em detrimento da ênfase anterior na sua fragmentação em nichos ou frações, é que a nova clivagem permitiria perceber não apenas a luta de classes entre a classe média e as demais classes sociais, mas também a luta de classes interna à classe média. Essa luta se dá exatamente entre a alta classe média e a massa da classe média (SOUZA, 2018b, p. 207208), desempenhando um papel crucial na dinâmica interna da classe média e, tendo em conta sua histórica relevância política na modernidade, da sociedade como um todo.

Esse caráter relacional - as relações da classe média com as demais classes e as relações entre alta classe média e baixa classe média - constitui um dos três pilares da sistematização teórica que Jessé Souza procura desenvolver em "A classe média no espelho". A ele soma-se um interesse pela exposição da gênese do "comportamento efetivo dos que fazem parte desta classe" e um interesse por uma exposição comparativa das similitudes e diferenças entre a classe média brasileira e outras 
classes médias pelo mundo (SOUZA, 2018b, p. 19).

Quanto à gênese do comportamento efetivo da classe média, sua exposição reproduz, embora de modo menos detalhado, o que ficou dito acima acerca da "topografia moral do Ocidente", da noção de habitus, e da predominância do capital cultural para as classes médias (SOUZA, 2018b, p. 23-75).

No que se refere à comparação entre a classe média do Brasil e de outros países do mundo, cabe destacar, por um lado, as semelhanças. Estritamente relacionadas ao problema da gênese do comportamento efetivo de seus integrantes na modernidade como um todo,

não existem diferenças relevantes na forma pela qual a classe média constrói seus privilégios nas sociedades modernas. Tais privilégios sempre se baseiam na apropriação do capital cultural mais valorizado e prestigioso (...).

Tampouco há diferença significativa entre a forma como essa apropriação injusta de capital cultural é legitimada (...). A meritocracia e o privilégio estético também estão na base de um processo que, no mundo todo, torna invisível e justificável o privilégio das camadas médias. (SOUZA, 2018b, p. 258-259).

Por outro lado, isso não significa que não haja diferenças relevantes entre as classes médias dos distintos países. A explicação dessas diferenças remonta tanto à história efetiva de cada país quanto aos mitos nacionais que se construíram em cada um deles para articular narrativamente essa história em uma estória dotada de unidade e sentido.

No Brasil, Jessé Souza identificará como "liberalismo vira-lata" o mito nacional hegemônico. Esse mito, em linhas 
gerais, traria em si conceitos como cordialidade, populismo e, sobretudo, patrimonialismo, enxergando no Estado e em qualquer de suas atuações o fantasma de um inimigo quaseontologicamente corrupto e localizando no mercado o reino das virtudes puras. A classe média brasileira seria "o suporte social mais importante do mito vira-lata da corrupção restrita à política" (SOUZA, 2018b, p. 260). Atualmente, esse mito seria uma vez mais reiterado no contexto do capitalismo financeiro global, reforçando a crítica radical ao Estado e a suas políticas principalmente sociais -, bem como fortalecendo a ideia de que todos estariam em situação muito melhor se deixados livres à disposição da lógica do mercado. Essa articulação narrativa dos fatos no mito nacional pátrio hegemônico escamotearia relações objetivas de dominação, fazendo da classe média muitas vezes vítima de sua própria incompreensão de si e de seu lugar social: despontam aqui sem dificuldade as figuras do "colaborador" e do "empresário de si", trabalhadores com frequência em situação de instabilidade e de precariedade, mas orgulhosos de sua suposta liberdade de fazer a si mesmo num mercado virtuoso.

Se essa é a dimensão mítico-narrativa que dá à classe média brasileira suas cores singulares, tal dimensão é complementada pela história efetiva do Brasil. Quanto a isso, novamente o elemento determinante é a escravidão: "somos os herdeiros da maior sociedade escravocrata do planeta" (SOUZA, 2018b, p. 69). Daí a consequência de a relação entre a classe média brasileira e as classes baixas do país ser marcada por aquele ódio e desprezo citados acima, uma relação típica de quem se considera cidadão em face de subcidadãos, gente em face de subgente, fazendo ecoar no século XXI a velha clivagem basilar de sociedades escravagistas.

O tom geral das análises de Jessé Souza sobre a classe média brasileira, porém, não é somente o de uma crítica destrutiva e que não enxerga saídas. Pese a que ele não tematize 
expressamente esta conclusão, as trajetórias reconstruídas de vidas concretas (SOUZA, 2018b, p. 169-204; 217-247) revelam que aqueles quatro nichos ou frações de classe - protofascista, liberal, expressivista e crítica - podem ser encontrados tanto na alta classe média quanto na massa da classe média, ainda que em proporções diferentes. Por conseguinte, tanto em uma quanto em outra se encontram pessoas adeptas do ideário fascista ou protofascista, pessoas que "são como que imunes ao aprendizado" (SOUZA, 2018b, p. 225). No entanto, também tanto em uma quanto em outra há nitidamente casos de importantes aprendizagens em curso na sociedade brasileira: "o aprendizado moral, social e político é possível em qualquer classe social" (SOUZA, 2018b, p. 216), ou seja, "ao mesmo tempo que se acirra a radicalidade manipuladora do fascismo, existe a possibilidade de aprendizado social na nossa quadra histórica" (SOUZA, 2018b, p. 255).

\section{APONTAMENTOS CRÍTICOS}

Exposto nas páginas anteriores o estado da arte da teoria das classes sociais de Jessé Souza, gostaria de apresentar algumas críticas que talvez possam contribuir para o relevante debate em que ela se insere.

Em primeiro lugar, na definição conceitual dos batalhadores como classe Jessé Souza destaca o capital familiar e a socialização religiosa como fatores capazes de gerar a aquisição daquelas disposições caras ao mercado de trocas capitalista e ao Estado burocrático modernos, disposições que distinguiriam os batalhadores da ralé. No entanto, a relação entre família, religião e classe não me parece suficientemente explicada.

Essa relação poderia, em princípio, ser esquematizada do seguinte modo: na ralé, a desestruturação familiar torna difícil 
a aquisição de pressupostos emocionais e morais relacionados a disposições como disciplina, autocontrole e pensamento prospectivo. Falta, pois, na ralé a aprendizagem de uma relação com o tempo, a aprendizagem de uma paciência projetiva em direção ao futuro. Isso se alastra para diferentes áreas da vida social. Uma delas, em que fica demasiado claro esse perfil, é a esfera religiosa. A religiosidade da ralé caracteriza-se pela força da "saída mágica", pelo elemento extraordinário que há de vir e solucionar, na lógica pura do milagre que irrompe ex nihilo, os problemas existentes (SOUZA, 2011, p. 205-240; 417).

$\mathrm{Na}$ classe dos batalhadores, diferentemente, prevaleceria uma religiosidade marcada pela "profecia exemplar do dia a dia", em que a crença no futuro é ao menos parcialmente deslocada da interação ser humano-transcendência e da lógica pura do milagre ex nihilo e trazida para interações face a face, sendo materializada em exemplos bastante concretos de pessoas outras que integram a mesma comunidade religiosa (SOUZA, 2012b, p. 320-321). Com isso, torna-se possível perante esses exemplos o desenvolvimento de uma identificação afetiva interna à esfera da religião e a consequente aquisição daquelas disposições ligadas à aprendizagem de uma relação paciente e projetiva com o tempo. Essa forma de vivência da religiosidade, por sua vez, condiz com o tipo familiar da classe dos batalhadores, no interior do qual tendencialmente se desenvolvem igualmente esses processos de identificação afetiva com exemplos e de aquisição dos pressupostos emocionais e morais referentes a disciplina, autocontrole, pensamento prospectivo.

O problema começa no momento em que os estudos empíricos mostram que, em casos típicos de famílias de ralé ${ }^{8}$, a religiosidade da "profecia exemplar do dia a dia" não apenas se soma a uma socialização familiar correspondente, mas

8 Conferir, por exemplo, os casos narrados em SOUZA, 2012b, p. 332$333 ; 335 ; 337 ; 339-340$. 
substitui precisamente a ausência dessa socialização familiar correspondente.

Sem dúvida, é esse o motivo que leva Jessé Souza a destacar, no fim do livro dedicado ao estudo da classe dos batalhadores, a socialização religiosa ao lado do capital familiar (SOUZA, 2012b, p. 367) ou mesmo tendo prioridade sobre ele (SOUZA, 2012b, p. 368) na determinação da classe, enquanto no início do mesmo livro a ênfase fica depositada só no capital familiar (SOUZA, 2012b, p. 50-51). Ademais, isso se relaciona à correção que ele imprime no diagnóstico acerca da ralé presente no livro anterior, reconhecendo que também ela está em constante mobilidade - o que significa que entre a ralé e os batalhadores há, necessariamente, certa zona de indistinção.

Contudo, o risco aqui me parece ser o de que essa zona de indistinção coloque em colapso toda a teoria. Afinal, o que leva algumas pessoas oriundas de famílias desestruturadas a procurarem comunidades religiosas caracterizadas pelas "saídas mágicas" e outras, oriundas da mesma maneira de tais famílias, a procurarem comunidades religiosas em que prevalece a "profecia exemplar do dia a dia"? Se não é a família o elemento que tendencialmente define a filiação a um ou outro tipo de religiosidade, o que seria? A presença física preferencial de igrejas com o primeiro perfil em locais habitados e/ou frequentados pela ralé, como favelas, periferias e o baixo centro de grandes cidades? Mas, se fosse isso, a determinação de uma tendência religiosa a partir da classe não teria dado lugar a uma relação entre classe, território e igrejas que, quando menos, atenua em muito a relevância explicativa da relação entre religião e classe para a compreensão da estrutura e da dinâmica de classes no Brasil? Se das famílias da ralé podem emergir fiéis tanto de uma quanto de outra forma de vivência da religião, pode-se ainda falar de uma religiosidade típica de cada uma das classes? E, mais grave em termos de teoria social, se 
a religião pode substituir a família no processo de aprendizagem da relação com o tempo, e se não puder ser determinada uma relação propriamente sociológica entre religião e arranjo familiar, não se tornaria aleatória a possibilidade de mobilidade da ralé em direção a integrar a classe dos batalhadores, ficando a cargo de fatores individuais não passíveis de explicação a escolha por um ou outro tipo de religiosidade e, consequentemente, a aquisição ou não de disposições que podem permitir a saída da ralé?

Para deixar claro meu ponto, não penso que não se possa determinar sociologicamente a relação entre religiosidade e arranjo familiar, nem entre religiosidade, arranjo familiar e classe. Nem pretendo negar in totum os argumentos de Jessé Souza ou oferecer uma explicação alternativa que passe, por exemplo, pela noção de território - embora acredite que essa seja uma boa direção complementar, e, claro, também a noção de território e de sua ocupação não é meramente cartográfica, mas densamente social e sociológica. Meu objetivo é apenas tentar mostrar que o modo como se encontra a explicação da relação, extremamente relevante para a compreensão da sociedade brasileira, entre família, religião e classe carece de maiores desenvolvimentos e novos passos explicativos na teoria das classes sociais de Jessé Souza.

Em segundo lugar, se a pertença a uma comunidade religiosa chega a substituir o capital familiar inexistente, é válido perguntar se outros espaços e tipos de socialização também não o poderiam fazer. Os casos empíricos que compõem a obra "Os batalhadores brasileiros" mostram a importância de experiências como o trabalho itinerante que força a saída da cidade natal e a continuada troca de cidade, o trabalho artesanal em que o indivíduo lida diretamente com seu objeto e o vai transformando com o passar do tempo a partir das necessidades percebidas na demanda do mercado, a presença e o engajamento em projetos 
esportivos, a vivência do serviço militar ${ }^{9}$. Tomando de empréstimo a B. Lahire a distinção entre a aquisição de disposições e os contextos de atualização dessas disposições, o panorama geral do livro aponta para a conclusão de que a aquisição dos pressupostos psicossociais associados a disciplina, autocontrole e pensamento prospectivo ocorreria na socialização familiar ou religiosa, enquanto essas outras experiências mencionadas neste parágrafo seriam somente contextos para sua atualização e para a aquisição de disposições secundárias - embora tal conclusão não apareça com clareza sistemática no livro como um todo. Mas seria mesmo apenas isso? Não haveria outros espaços e tipos de socialização, para além da familiar e da religiosa, que poderiam substituí-las na própria aquisição das disposições, fossem as experiências aqui mencionadas ou outras? Quanto a essas experiências aqui mencionadas, a diferença entre aquisição de disposições e atualização de disposições realmente se sustenta para todas elas? Se for possível mapear esses outros espaços e tipos de socialização, projetos culturais e esportivos desenvolvidos em comunidades pobres seriam bons candidatos? Se o forem, não seria o caso de revalorizar esses projetos em um novo quadro teórico, o que permitiria rever a crítica a eles elaborada, por exemplo, no livro dedicado à ralée ${ }^{10}$ ?

Em terceiro lugar, também a abordagem da relação entre raça e classe requer explicações mais detalhadas e desenvolvimentos ainda não realizados. $O$ argumento de Jessé Souza quanto esse ponto afirma que na estratificação social 9 Conferir, por exemplo, os casos narrados em SOUZA, 2012b, p. 155160.

10 SOUZA, 2011, p. 89-100. É interessante destacar que já ali a crítica de Jessé Souza não desconsidera totalmente o valor desses projetos, mas procura apontar sua limitação: "As associações de hip-hop e de arte e cultura são invenções maravilhosas, fruto de trabalho de pessoas dedicadas e comprometidas. Mas eles tocam algumas centenas ou alguns milhares. $\mathrm{E}$ não tocam também na base da autoconfiança e do reconhecimento social moderno (...)" (SOUZA, 2011, p. 99). 
brasileira o fator racial seria secundário diante do fator classe. Ou seja, o elemento racial não seria indiferente para a compreensão da estratificação da sociedade, mas atuaria como um elemento que se soma - no caso de pessoas negras ou indígenas, por exemplo - ao elemento primário que é a classe. Essa seria a tônica de seu diálogo crítico com Florestan Fernandes: este teria conseguido enxergar em seus estudos empíricos a relevância das "precondições sociais independentes da cor que condicionam a situação de marginalidade" (SOUZA, 2012a, p. 159) da população negra, precondições relacionadas exatamente aos pressupostos psicossociais que asseguram tendencialmente sucesso na luta de classes simbolicamente mediada. Mas se teria equivocado ao não levar às últimas consequências esses dados empíricos, mantendo-se preso a uma explicação da exclusão negra que "enfatiza o dado secundário da cor", jogando

água no moinho da explicação economicista e evolucionista de tipo simples, que supõe ser a marginalização algo temporário, modificável por altas taxas de crescimento econômico, as quais, de algum modo obscuro, terminariam por incluir todos os setores marginalizados. (SOUZA, 2012a, p. 160)

Sem entrar no mérito das análises que Jessé Souza faz da obra de F. Fernandes, o modo como ele coloca a questão da relação entre raça e classe deixa uma série de perguntas no ar. Sua proposta inicialmente mostra-se, por certo, coerente com sua teoria das classes sociais. Mas, se os estudos da ralé e dos batalhadores permitem entender que o preconceito racial sofrido pela população negra é algo que se soma a uma condição de classe compartilhada com a população branca, no mínimo seria necessário um estudo da situação da população negra presente, ainda que em escala mínima, nas classes média e alta para 
diagnosticar com mais clareza a possível autonomia ou não do problema racial no Brasil: se o que conta, em última instância, são os atributos psicossociais de classe, por que permaneceria o preconceito racial - como me parece ser o caso - mesmo quando não restam dúvidas sobre a posse desses atributos, verificada em carreiras de sucesso no mercado ou no Estado? As pesquisas referentes a essas duas classes estão, como dito acima, ainda em fase inicial. É possível que, com seu andamento, a explicação até agora vigente da relação entre raça e classe ganhe novos argumentos, com maior força de convencimento, ou seja abandonada em favor de uma nova abordagem. Como quer que seja, neste momento, tal explicação não se revela suficientemente adequada.

\section{CONSIDERAÇÕES FINAIS}

Para terminar, gostaria de fazer um último apontamento crítico, referente ao problema da relação entre a ralé e a atuação política. A aceitação de que existe uma zona de indiferenciação entre a ralé e os batalhadores, aliada à discussão sobre a consciência e o posicionamento políticos dessa segunda classe (SOUZA, 2012b, p. 199-255), relativiza a tese inicial sobre a passividade política da ralé. Mas, embora relativizada, essa tese permanece sem ser revista. Como afirmei na introdução, um dos três conjuntos de teses e argumentos que se apresentam como resultados principais do projeto teórico de Jessé Souza é uma teoria da relação entre ideias e práticas sociais, caracterizada por uma crítica ao discurso predominante sobre o Brasil nas ciências sociais brasileiras ao longo do século XX. Elementos como populismo, clientelismo, atraso e pré-modernidade são centrais dentro desse discurso dominante que, segundo Jessé Souza, serviu como legitimação perfeita para a continuação da dominação de classes no Brasil (SOUZA, 2015, p. 12). Porém, 
outro elemento desse discurso sempre foi a incompetência das classes populares para a política e, especialmente, para a democracia. Até que ponto a tese de Jessé Souza sobre a passividade política da ralé não acaba, contra todas as suas pretensões declaradas, engrossando o caldo dessa leitura dominante nas ciências sociais brasileiras? Esse problema parece agravar-se na medida em que, em seu livro mais recente, Jessé Souza ensaia depositar uma esperança política demasiada no nicho crítico da massa da classe da média: "É essa parte da massa da classe média que pode assegurar uma luz no fim do túnel ao reconhecer sua situação de exploração e sua ligação umbilical ao destino das classes populares" (SOUZA, 2018b, p. 276). Mais uma vez - como em tantas outras se afirmou ao longo da história do Brasil - a possibilidade de mudanças na situação social e econômica dessas classes populares dependeria da tutela política das classes médias?

Essa minha pergunta estaria equivocada se se tratasse apenas de não concordar, desde o princípio e de maneira irredutível, com as consequências da tese da incompetência política dos pobres: nesse caso, a argumentação teórica estaria cedendo perigosamente espaço aos interesses estratégicos da política. Mas não: as razões de minha indagação são propriamente teóricas. Não se trata de enxergar a passividade política da ralé e querer negá-la em face dos riscos políticos dessa tese. Trata-se, em vez disso, de sustentar que a passividade política da ralé é uma tese que não se mantém de pé à luz da historiografia mais rigorosamente construída - dos tempos coloniais até os dias de hoje ${ }^{11}$. Ou seja, para permanecer defendendo essa tese, Jessé Souza precisaria lidar com toda uma história de lutas sociais que, se eu não estiver enganado, emergiram em contextos 11 Tenho procurado trabalhar esse ponto, em boa medida ainda introdutoriamente e em tom ensaísta, em alguns textos, escritos individualmente ou em coautoria. Conferir, por exemplo, GOMES, 2015; GOMES, 2017; GOMES; CATTONI DE OLIVEIRA, 2012. 
muito similares àqueles que ele descreve como sendo o da ralé estrutural.

Ao lidar com essa história de lutas travadas muitas vezes a partir da miséria quase absoluta, acredito que dificilmente tal tese continuaria mostrando a mesma plausibilidade. $\mathrm{O}$ abandono dela, por seu turno, seria possivelmente o último passo que faltaria para que Jessé Souza finalmente estivesse livre daquela tradição das ciências sociais por ele acusadas como uma "inteligência tola" (SOUZA, 2015): tradição à qual ele afirmava ter estado filiado até a guinada teórica de 2000 (SOUZA, 2000, p. 9) e da qual desde então tem procurado continuamente afastar-se.

\section{REFERÊNCIAS}

FRANCO, Maria Sylvia de Carvalho. Homens livres na ordem escravocrata. 4a. ed. São Paulo: Unesp, 1997.

GOMES, David F. L. "Houve mão mais poderosa"?: Soberania e Modernidade na Independência do Brasil. Belo Horizonte: Initia Via, 2015.

GOMES, David F. L. Jessé Souza, Brasil e a "modernização seletiva”. Revista Quaestio Iuris, no prelo, 2019.

GOMES, David F. L. Sobre a República nos tempos do Império. Revista Quaestio luris, vol. 10, n. 03, Rio de Janeiro, 2017, p. 2108-2134.

GOMES, David F. L.; CATTONI DE OLIVEIRA, Marcelo Andrade. Independência ou sorte?: ensaio de história constitucional do Brasil. Revista da Faculdade de Direito (UFPR), v. 55, 2012, p. 19-37.] 
HABERMAS, Jürgen. Teoría de la acción comunicativa. 2t. Trad. Manuel Jiménez Redondo. Madrid: Trotta, 2010.

HABERMAS, Jürgen. Para a reconstrução do materialismo histórico. Trad. Rúrion Melo. São Paulo: Unesp, 2016.

NOBRE, Marcos; REPA, Luiz (orgs.). Habermas e a reconstrução. Campinas: Papirus, 2012.

SOUZA, Jessé. A classe média no espelho: sua história, seus sonhos e ilusões, sua realidade. Rio de Janeiro: Estação Brasil, 2018b.

SOUZA, Jessé. A construção social da subcidadania: para uma sociologia política da modernidade periférica. Belo Horizonte; Rio de Janeiro: UFMG; IUPERJ, 2012a.

SOUZA, Jessé. A elite do atraso: da escravidão à Lava Jato. Rio de Janeiro: Leya, 2017.

SOUZA, Jessé. A modernização seletiva: uma reinterpretação do dilema brasileiro. Brasília: UnB, 2000.

SOUZA, Jessé. A radiografia do golpe: entenda como e por que você foi enganado. Rio de Janeiro: Leya, 2016.

SOUZA, Jessé. A ralé brasileira: quem é e como vive. 1a. reimp. Belo Horizonte: UFMG, 2011.

SOUZA, Jessé. A subcidadania brasileira: para entender o país além do jeitinho brasileiro. Rio de Janeiro: Leya, 2018a.

SOUZA, Jessé. A tolice da inteligência brasileira: ou como o país se deixa manipular pela elite. Rio de Janeiro: Leya, 2015. 
SOUZA, Jessé. Os batalhadores brasileiros. Nova classe média ou nova classe trabalhadora? Belo Horizonte: UFMG, 2012b.

$$
\begin{aligned}
& \text { Recebido em | 31/01/2019 } \\
& \text { Aprovado em | 17/04/2019 }
\end{aligned}
$$

Revisão Português/Inglês | David Francisco Lopes Gomes

\section{SOBRE O AUTOR | ABOUT THE AUTHOR}

DAVID FRANCISCO LOPES GOMES

Doutor em Direito pela Universidade Federal de Minas Gerais (UFMG). Professor efetivo da Faculdade de Direito da UFMG, nos cursos de graduação em Direito e em Ciências do Estado e no Programa de Pós-Graduação em Direito. Subcoordenador do curso de graduação em Ciências do Estado da UFMG. E-mail: davidflgomes@yahoo.com. 